Proc. Indian Acad. Sci. (Earth Planet. Sci.), Vol., 91, No. 1, March 1982, pp. 79-83. (c) Printed in India.

\title{
Induction by long period geomagnetic variations in the Indian sub-continent
}

\author{
MITA RAJARAM, B P SINGH and S Y WAGHMARE \\ Indian Institute of Geomagnetism, Colaba, Bambay 400 005, India
}

MS received 6 February 1981; revised 8 Seplember 1981

\begin{abstract}
In the present paper storm time variations and 27-day geomngnetic periom dicity have been analysed to estimate the depth of the substitute conductor, assuming an infinitely (super) conducting core model of the earth. The advantage of using data from a restricted longitude range is that the uncertainties arising from lateral contrasts in the upper mantle and contributions from Sq current systems are considerably rediced. The result of the present analysis, which has been done in the time domain, gives a value of $522 \mathrm{~km}$ for the deptlh of the subsitute conductor in case of storm tine variations which rises to $870 \mathrm{~km}$ for 27 -day recurrent storms. A higher value of the depth for 27-day variations indicate that the rise in conductivity inside the earth is not like a step function rather is a gradrial one. The value of $522 \mathrm{~km}$ for storm time variations for the Indian region is smaller than the global average. This is natural to expect because the Indian sub-continent is known to be a tectonically active region.
\end{abstract}

Keywords. Storm tine variations; geomagnetic periodicity.

\section{Introduction}

Features of transient geomagnetic variations have been identified as useful diaguostic tools to probe the deeper interior of the eartl. A major limitation has been the availability of a good network of observatories. Even with a limited number of observatories, accurate results can be obtained for those geomagnetic variations, where the source field geometry is accurately known. In the present paper we analyse data for sc-storm-time variations and 27-day recurrent geomagnetic activity. Both these variations have fairly well-known source field geometry and in both cases the potential of the field is very well represented by a $P_{1}^{\circ}(\cos \theta)$ term (Chapman and Price 1930; Eckhardt et al 1963). Chapman and Price (1930) have determined, using a uniform core model, both the conductivity and depth of penetration which best fit the sc-storm time data. In this paper we have used the infinitely (super) conducting core model (Jady et al 1979); the difference in the two models is given by Banks (1969). We have used data from observatories on the Indian sub-continent which have a very small longitudinal spread. It may be emphasized that, Kingan et al (1980) have expressed doubt about the validity of the assumption that the Dst field is independent of longitude. By restricting ourselves to a very small range of longitudes, any local time dependence of the Dst field, if present, will not affect the analysis. The aim of the present study is to find the depth of the substitute conductor using storm time variations and 27-days recurient storms, assuming a super conducting core model. The 27-day recurrent storms bave been chosen from Bartel's 
diagram. We wish to see if the response of the earth is the same for both these variations. Further, considering the problems associated with accurate determination of phase we have done the analysis in time domain. We know that India lies on a tectonically active area, the Indian plate is still drifting (Grough 1977). Information on the electrical structure of its deeper layer is therefore of special significance in wider perspectives of geophysics.

\section{Analysis}

For the analysis of both the sc-storm-time variations and the 27-day recurrent storms, we have assumed that in the general magnetic potential of these fields, only the first term $(n=1)$ is dominant and the components of the magnetic field at the surface of the earth are given by

$$
X=-\left(e_{1}+i_{1}\right) \sin \theta \text { and } Z=\left(e_{1}-2 i_{1}\right) \cos \theta,
$$

(Rikitake and Sato 1957), where $\theta$ is the geomagnetic colatitude of the place and $e_{t}$ and $i_{1}$ are respectively the contributions from external and internal current systems. In the Indian region, $X$ and $H$ are nearly the same as the declination, $D$, is very small. For any given time, a least squares fit to the observed $H$ and $Z$ variations at the different stations is made to estimate $e_{1}$ and $i_{1}$.

Further, using an infinitely conducting core model of the earth, the radius of the inner conducting core is determined, following Jady et al (1979). From the evaluated $e_{1}$ and $i_{1}$ values for each of the $N$ time intervals, the parameter $\alpha$ is calculated.

$a$ is defined by

$$
a=\frac{\sum_{j=1}^{N} e_{1}\left(t_{j}\right) i_{1}\left(t_{j}\right)}{\sum_{j=1}^{N}\left[e_{1}\left(t_{j}\right)\right]^{2}} .
$$

From $a$ the normalised radius, $q$, of the perfectly conducting core is evaluated $\left(a=q^{3 / 2}\right.$ ) from which the depth of the perfect substitute conductor is estimated for both sc-storm-time variations and 27-days recurrent storms. The depth of the substitute conductor is given by the relation: $d=(1-q) R$; where $R$ is radius of the earth.

\subsection{Storm-time variation}

The magnetic storm of November 21-22, 1975 has been used for this study. The details of the data used and their analysis are given in Rajaram et al (1979). The standard errors in $e_{1}$ and $i_{1}$ were computed as in Anderssen and Seneta (1969). Plot of $e_{1}$ and $i_{1}$ thus obtained is given in figure 1. We shall call this $e_{\text {obs }}$ and $i_{\text {obs. }}$. Then we evaluated $a$ from (1). We obtained $a=0.38$ and $i_{1}$ was calculated as $i_{1}=a e_{\text {obs }}$ 
( $t_{1}$ ) (Jady et al 1979). We shall denote this by $i_{\text {cal. }}$. A plot of $i_{\mathrm{cal}}$ is also given in figure 1. It may be noted that the observed and calculated values agree well. This value of $\alpha$ gives the depth of the perfect conductor at $522 \mathrm{~km}$.

\subsection{7-days variation}

The signal of the 27-day recurrent storm is usually very weak and therefore to be able to isolate the signal, the method of superposed epoch analysis (Chapman and Bartels 1940 ) was used. From the Bartels diagram sequences of $27-d$ cycles of well-defined recurrent storms were noted. The spectral peaks of the $27-d$ period and its harmonics are best defined during low levels of solar activity (Banks 1969), therefore, we selected the sequence of five $27-d$ recurrent storms in 1976 (rotation numbers 1948 to 1952), period of solar minimum. From the Bartels diagram the first day of each 27-d rotation period was taken as the key day. To remove shorter period fluctuations, five-day running mean for the entire period was taken. Therefore data collection started 2 days before the key day of the first cycle up to 2 days after the end of the fifth cycle. Thus daily mean hourly $H$ and $Z$ values of the different Indian stations were taken from January 11 to May 28, 1976. Table 1 lists the stations used for this

Table 1. The geographic and geomagnetic co-ordinates of the observatories whose records have been used in daily analysis of 27 -day variations

\begin{tabular}{|c|c|c|c|c|c|}
\hline \multicolumn{2}{|c|}{ Station } & \multicolumn{2}{|c|}{ Geographic } & \multicolumn{2}{|c|}{ Geomagnetic } \\
\hline Name & Abbreviation & Latitude & Longitude & Latitude & Longitude \\
\hline Trivandrum & TRV & $8^{\circ} \quad 29^{\prime} \mathrm{N}$ & $76^{\circ} \quad 57^{\prime} \mathrm{E}$ & $l \cdot 11^{\circ} \mathrm{S}$ & $146.83^{\circ} \mathrm{E}$ \\
\hline Kodaikanal & $\mathrm{KOD}$ & $10^{\circ} 14 \mathrm{~N}$ & $77^{\circ} \quad 29^{\prime} \mathrm{E}$ & $0.57^{\circ} \mathrm{N}$ & $147.53^{\circ} \mathrm{E}$ \\
\hline Annamalainagar & ANR & $11^{\circ} 22^{\prime} \mathrm{N}$ & $79^{\circ} 41^{\prime} \mathbf{E}$ & $1.51^{\circ} \mathrm{N}$ & $149 \cdot 81^{\circ} \mathrm{E}$ \\
\hline Hyderabad & HYD & $17^{\circ} 25^{\prime} \mathrm{N}$ & $78^{\circ} \quad 33^{\prime} \mathbf{E}$ & $7 \cdot 61^{\circ} \mathrm{N}$ & $149 \cdot 35^{\circ} \mathrm{E}$ \\
\hline Alibag & ALB & $18^{\circ} 38^{\prime} \mathrm{N}$ & $72^{\circ} \quad 52^{\prime} \mathrm{E}$ & $9.43^{\circ} \mathrm{N}$ & $144 \cdot 06^{\circ} \mathrm{E}$ \\
\hline Ujjain & UJN & $23^{\circ} 11^{\prime} \mathrm{N}$ & $75^{\circ} \quad 49^{\prime} \mathrm{E}$ & $13.50^{\circ} \mathrm{N}$ & $147 \cdot 00^{\circ} \mathrm{E}$ \\
\hline Shillong & SHL & $25^{\circ} 34^{\prime} \mathrm{N}$ & $91^{\circ} 53^{\prime} \mathbf{E}$ & $14 \cdot 6^{\circ} \mathrm{N}$ & $162 \cdot 04^{\circ} \mathrm{E}$ \\
\hline Jaipur & JAI & $26^{\circ} 35^{\prime} \mathrm{N}$ & $75^{\circ} \quad 48^{\prime} \mathrm{E}$ & $17 \cdot 20^{\circ} \mathrm{N}$ & $147 \cdot 40^{\circ} \mathrm{E}$ \\
\hline Sabhawala & SAB & $30^{\circ} 22^{\prime} \mathrm{N}$ & $75^{\circ} \quad 47^{\prime} \mathrm{E}$ & $20 \cdot 52^{\circ} \mathrm{N}$ & $150 \cdot 11^{\circ} \mathrm{E}$ \\
\hline
\end{tabular}

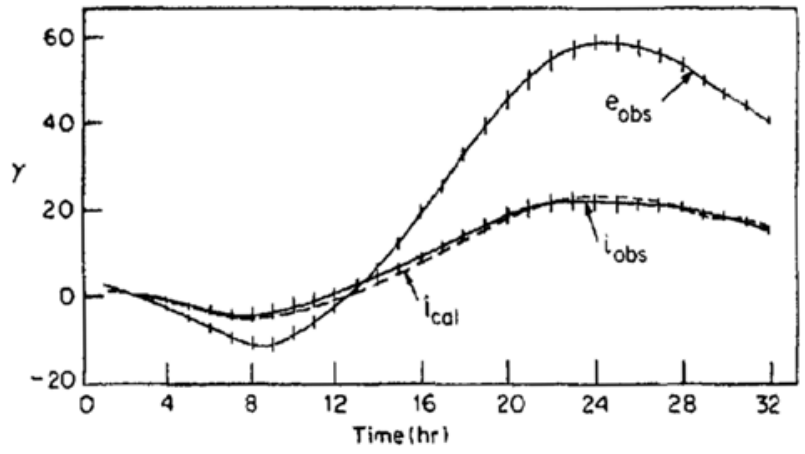

Figure 1. Variations of the observed $e(t)$ and $i(t)$ and calculated $i(t)(--)$ for the storm-time variations of 1975, November 21-22. Standard errors in observed $e(t)$ and $i(t)$ and also shown. 
analysis and their geomagnetic co-ordinates. After taking the five-day running mean, the various 27- $d$ cycles were stacked. The mean of the five cycles for each day in the $27-d$ period was noted. Further, the mean of the first three days was removed from each of the 27-days. This was done for each of the nine stations listed in table 1. Least square fit of the observed $H$ and $Z$ values were then made, to obtain $e_{\text {obs }}$ and $i_{\text {obs }}$, for each of the 27-days. Further, $a$ was evaluated from (1) and was found to be $=0.32$ from which $i_{\text {cal }}$ was calculated for each day. Plots of $e_{\mathrm{obs}}, i_{\mathrm{obs}}$ and $i_{\text {cal }}$ are given in figure 2. Here again the agreement between $i_{\text {obs }}$ and $i_{\text {cal }}$ is excellent. The depth of the perfectly conducting core evaluated from the 27 -day variation is $870 \mathrm{~km}$.

It may be added that a similar analysis carried out using the data directly for a single 27-day cycle (March 7-April 2, 1976) did not yield a good fit to the observed variations. A plot of the fit of the observed $H$ and $Z$ variations for 16 th day, when the signal is strongest is given in figure 3 . It is evident that the fit using a single 27-day period is poor as the signal to noise ratio, particularly in $Z$ is very low. For comparison a plot of the fit to the observed $H$ and $Z$ variations using the superposed epoch analysis for the 16 th day, is also made in the same figure (3a). From the figure it is clear that to be able to make any study related to the 27-day variation, the choice of data is of paramount importance, so that the signal can be isolated from the background noise.

\section{Discussion and conclusions}

The depth of the substitute conductor over the Indian sub-continent, as obtained in the present sc-storm-time analysis is $522 \mathrm{~km}$. This is shallower when compared with the depth estimated by various workers, which are listed by Jady et al (1979). Before making any critical comparison, it would be proper to emphasize that lateral contrasts are now known to exist in the upper mantle and an estimate of the depth of substitute conductor from storm-time analysis using data from observatories spread all over the globe can only be an indication of a global average value. However, one point is obvious that a smaller value for this depth under the Indian sub-continent is natural to expect because the Indian sub-continent is still drifting, which indicates that it might be floating over a well-developed asthenophere providing a medium of larger conductivity at shallower depths. The depth of this substitute conductor for the 27-d

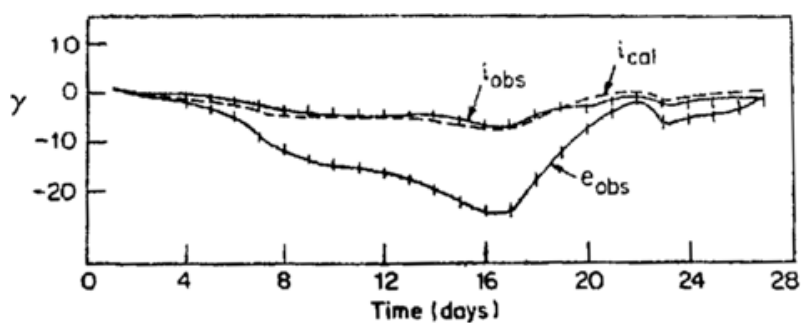

Figure 2. Variations of observed $e(t)$ and $i(t)$ for the 27-day variations of 1976 January 11 to May 28, using the superposed epoch method. Standard errors in $e(t)$ and $i(t)$ are shown. Calculated $i(t)(--)$ is also plotted. 


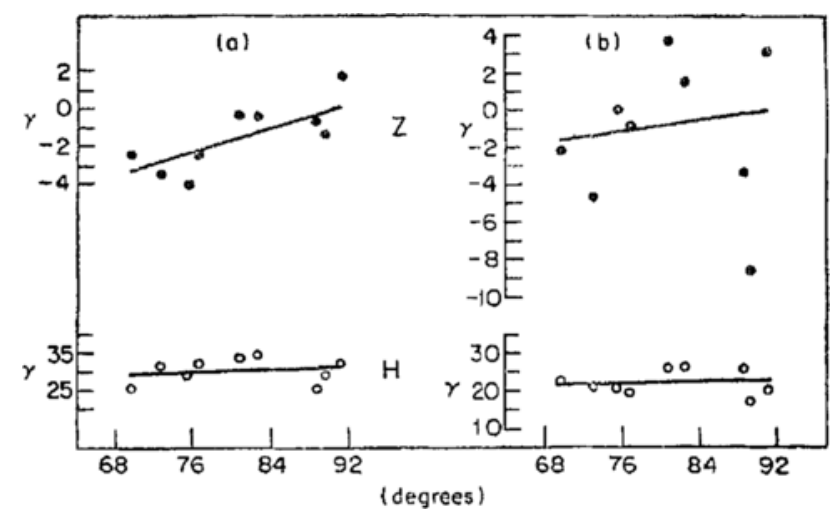

Figure 3. Plot of the observed horizontal $(O)$ and vertical ( $)$ magaetic fluetuations against colatitude (in degrees) for the 16th day of the 27-d variation (a) using the superposed epoch analysis (b) using data directly for a single 27-d recurrent storm period. The solid lines are least squares fit of the $P_{\perp}^{o}$ mode to the observed $H$ and $Z$ values.

analysis is found at $870 \mathrm{~km}$ which is a bit larger than that obtained for the sc-stormtime variations, indicating that the response of the earth is not frequency independent for the range of periods from a few days to a few tens of days. In case of a step function, where the conductivity rises sharply to infinity, the depth of penetration would be frequency independent. The present results indicate that one should not expect the conductivity $\sigma$ to rise sharply in the earth's interior, rather the increase in $\sigma$ with depth is gradual.

It may be added that analysis of the $27-d$ variations was also carried out in the frequency domain as has been done, by most of the earlier workers (Banks 1969). But for the low latitudes of the Indian region, the $Z$ amplitude of the 27- $d$ variation is very small and consequently the signal to noise ratio is too weak to provide reliable estimates of the response function. Particular difficulty was encountered in estimating phase values.

\section{References}

Anderssen R S and Seneta E 1969 J. Geophys. Res. 742768

Banks R J 1969 Geophys. J. R. Astron. Soc. 17457

Chapman S and Bartels J 1940 Geomagnetism Vol. 1 (Oxford: Clarendon Press)

Chapman S and Price A T 1930 Philos. Trans. R. Soc. A229 427

Eckhardt D, Larner K and Madden T 1963 J. Geophys. Res. 686279

Gough D I 1977 Earth Planet. Sci. Lett. 34360

Jady R J, Marshall R T and Morgan K 1979 Phys. Earth Planet. 206

Kingan P A, Bloomfield P and Anđerssen R S 1980 J. Geomagn. Geoelectr, 3257

Rajaram M, Singh B P, Nityananda N and Agarwal A K 1979 Geophys. J. R. Astron. Soc. 56.127

Rikitake T and Sato S 1957 Bull. Earthq. Res. Inst. Tokyo 357 